\title{
Undifferentiated sarcoma of the heart: A rare clinicopathologic presentation
}

\author{
Augusto Orlandi, MD, a Amedeo Ferlosio, BM, ${ }^{\text {a }}$ Vladimiro Dell'Anna, MD, ${ }^{a}$ \\ Raffaella Quitadamo, MD, ${ }^{a}$ Antonio Pellegrino, MD, ${ }^{\mathrm{b}}$ and \\ Luigi Giusto Spagnoli, MD, ${ }^{a}$ Rome, Italy
}

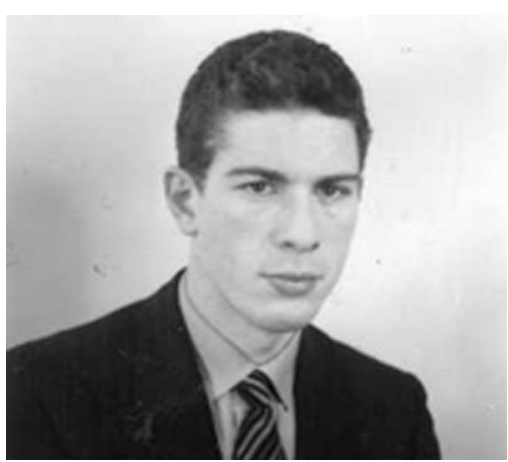

Dr Orlandi
$\mathrm{W}$ ith an incidence of $0.0017 \%$ to $0.28 \%$ in selected autopsy series, ${ }^{1-3}$ primary tumors of the heart are extremely uncommon. According to an Armed Forces Institute of Pathology-reported series, ${ }^{4}$ $25 \%$ behave in a malignant manner, and only $2 \%$ are undifferentiated sarcomas. The latter generally occupy the left atrium (81\%) and exhibit a solid and infiltrative pattern. ${ }^{4}$ This study reports a rare case of undifferentiated sarcoma arising from the fossa ovalis of the interatrial septum at clinical presentation, with biatrial involvement and an unusual echocardiographic pattern related to the pseudocystic nature of the tumor, which mimicked an atrial myxoma.

\section{Clinical Summary}

A 28-year-old previously healthy woman was admitted for sudden dyspnea on exertion and ingravescent orthopnea. The patient also had epigastric swelling and declivitous edema. The radiograph showed a bilateral pleural effusion and an accentuation of pulmonary pattern. An electrocardiogram showed sinus rhythm, but with an incomplete right bundle branch block indicative of anomalous pulmonary venous drainage. A 2-dimensional echocardiogram (Figure 1, A) revealed a pronounced pericardial effusion and a biatrial tumoral mass that totally occupied the left atrium with a nonhomogeneous pattern. The clinical diagnosis was atrial myxoma.

At operation, an ovoid mass was seen that measured $7.5 \times 4 \times$ $3.4 \mathrm{~cm}$ in the left atrium and $4.5 \times 3.2 \times 3.4 \mathrm{~cm}$ in the right atrium, with a common origin arising from the fossa ovalis. The mass was completely removed, along with the interatrial septum,

From Anatomic Pathology ${ }^{\mathrm{a}}$ and Cardiovascular Surgery ${ }^{\mathrm{b}}$ Institutes, Tor Vergata University, Rome, Italy.

Received for publication Dec 26, 2001; accepted for publication Jan 4, 2002

Address for reprints: Augusto Orlandi, MD, Anatomic Pathology Institute, Department of Biopathology, Tor Vergata University of Rome, Via della Ricerca Scientifica, 00133 Rome, Italy (E-mail: orlandi@uniroma2.it).

J Thorac Cardiovasc Surg 2002;124:192-3

Copyright @ 2002 by The American Association for Thoracic Surgery $0022-5223 / 2002 \$ 35.00+0 \quad \mathbf{1 2 / 5 4} / \mathbf{1 2 2 7 8 7}$

doi: $10.1067 / \mathrm{mtc} .2002 .122787$ which was replaced with an autologous pericardial patch. The surgical treatment required cardiopulmonary bypass. A macroscopic examination of the tumor showed a well-defined surface with an ovoid shape. The color was yellow-gray. A cut-surface examination (Figure 1,B) confirmed the pseudocystic appearance of the tumor. The histologic examination (Figure 2, A) showed groups of large and round spindle cells with oval nuclei, prominent nucleoli, and sparse cytoplasm in a loose edematous, Alcian staining, extracellular matrix with a focal pseudocystic and microcystic appearance. The neoplastic cells exhibited a high degree of nuclear pleomorphism and mitotic activity. Focal necrosis was also present. On immunohistochemical investigation, the neoplastic cells stained positively for vimentin but negatively for cytokeratin, S-100, smooth muscle actin, and leukocyte markers. No cross striations were identified in the elongated, spindle-shaped cells. Electron micrographs (Figure 2, B) showed an evident rough endoplasmic reticulum with some cystlike dilatations and large mitochondria, embedded in an amorphous, finely granular matrix. A histologic diagnosis of undifferentiated sarcoma was made. Two years later, the patient is healthy and free of any sign of disease.

\section{Comment}

Primary malignant tumors of the heart are extremely uncommon. ${ }^{1-3}$ Most are sarcomas, including angiosarcoma, lymphosarcoma, giant cell sarcoma, fibromyxosarcoma, leiomyosarcoma, neurogenic sarcoma, and rhabdomyosarcoma. Undifferentiated sarcomas show a frequency varying from $0 \%$ to $24 \%$ in all reported series. ${ }^{4}$ This high variability in part reflects inadequate sampling and a lack of adequate material for complete immunohistochemical and ultrastructural analysis. Undifferentiated sarcomas proliferate rapidly, and generally patients die of progressive heart failure, although distant metastases are also encountered at diagnosis. ${ }^{1}$ A more useful diagnostic tool is the transthoracic and transesophageal 2-dimensional echocardiogram, which usually accurately identifies the shape, dimension, and possible valve involvement and invasion of myocardium, thus providing information necessary for an optimal therapeutic approach. This case is of interest both for the unusual clinical presentation, which mimicked an atrial myxoma, and for its pathologic features. There are no cases of undifferentiated sarcoma with biatrial involvement described in the literature. Echocardiographically, the tumor presented a nonhomogeneous appearance without any malignant as- 

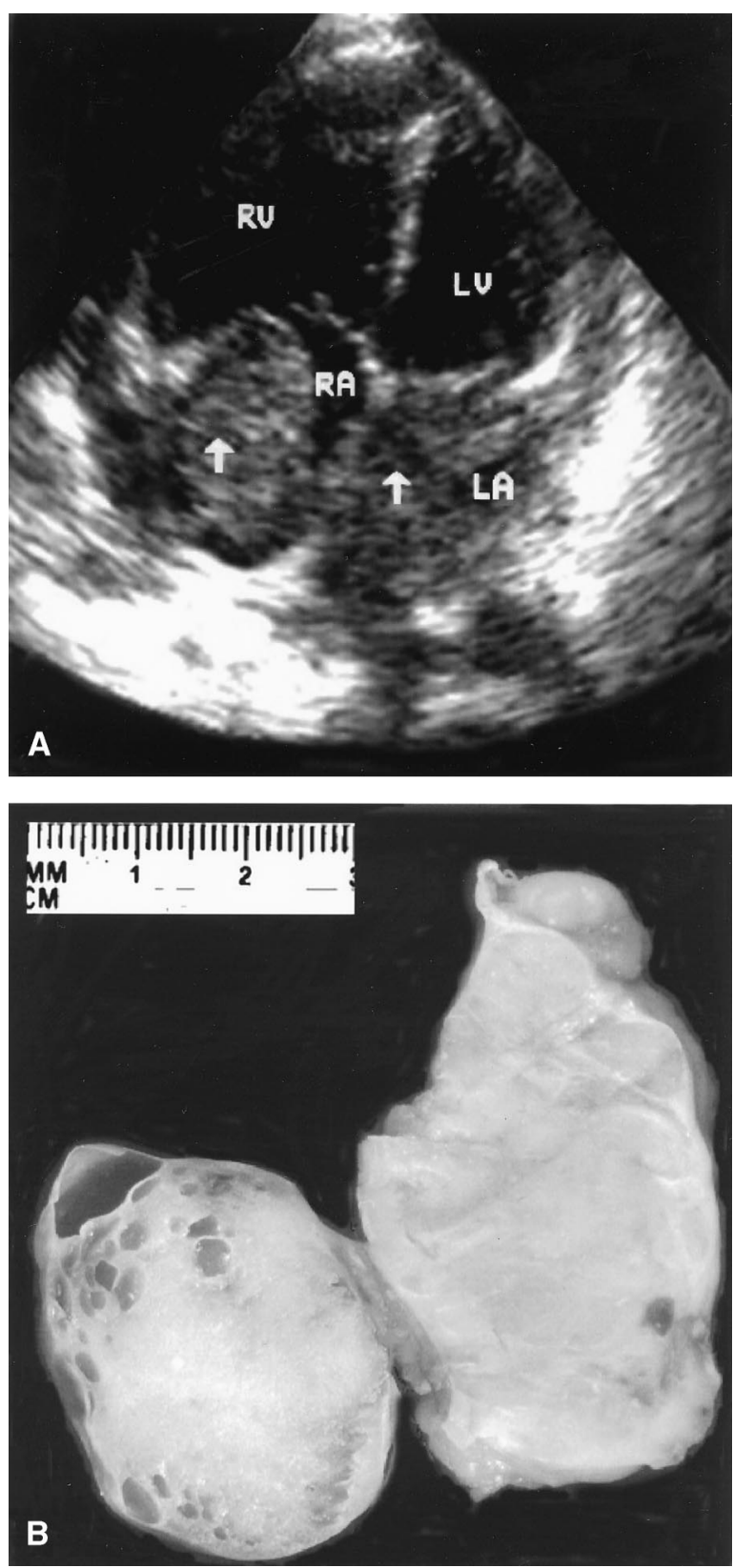

Figure 1. A, Two-dimensional transthoracic echocardiogram showing left (LA) and right atrium (RA) totally occupied by tumoral masses (arrows). $R V$, Right ventricle; $L V$, left ventricle. $B$, Cut surface of tumor with alternating solid and cystic areas.

pect, such as irregular shape or invasion of myocardium, and it was more like a common atrial myxoma, which usually arises from the fossa ovalis. ${ }^{5}$ A pseudocystic appearance is also highly unusual in undifferentiated sarcoma. This might derive from the accumulation of a hydrophilic proteoglycan-rich extracellular matrix as a consequence of deregulated synthesis by neoplastic cells. The ultrastructural secretory aspect of the cells, resembling that of primitive mesenchyma, supports this concept. It is likely that the patient's relatively good follow-up after 2 years is related to the site of
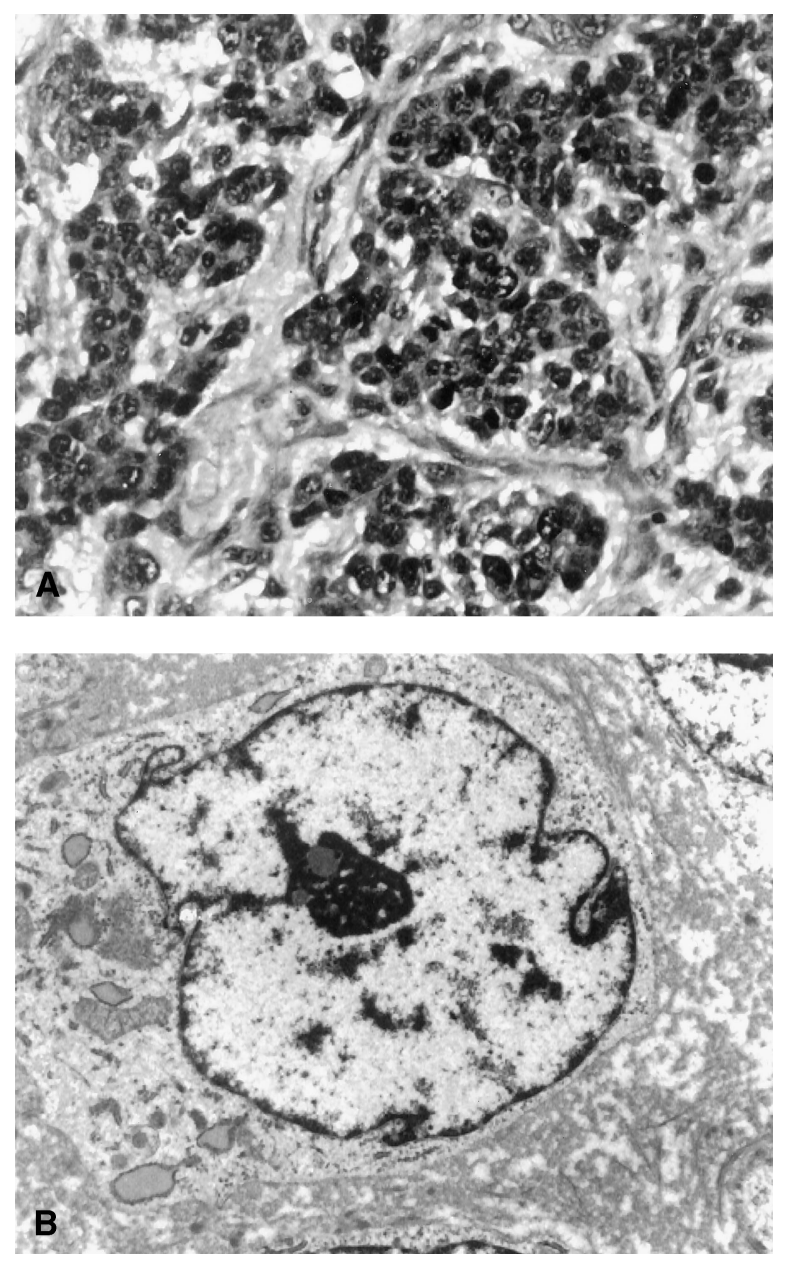

Figure 2. A, Microscopic examination of undifferentiated sarcoma showing groups of atypical round cells with sparse cytoplasm in loose mesenchymal matrix (hematoxylin and eosin stain, original magnification $\times 200$ ). B, Electron micrograph of a neoplastic cell with evident rough endoplasmic reticulum with some cystlike dilatations and large mitochondria (original magnification $\times 4300$ ).

origin and to the smooth profile without infiltrative edges, although other cases are needed to confirm this hypothesis.

\section{References}

1. Allard MF, Taylor GP, Wilson JE, McManus BM. Primary cardiac tumors. In: Goldhaber SZ, Braunwald E, editors. Atlas of heart diseases, vol 3: cardiopulmonary disease and cardiac tumors. St Louis: Mosby-Year Book; 1995. Chap 15, p. 1-22.

2. Reynen K. Frequency of primary tumors of the heart. Am J Cardiol. 1996;77:107.

3. Lam KY, Dickens P, Chan AC. Tumors of the heart: a 20-year experience with a review of 12,485 consecutive autopsies. Arch Pathol Lab Med. 1993;117:1027-31.

4. Burke A, Virmani R. Tumors of the heart and great vessels. In: Atlas of tumor pathology, fascicle 16, Washington DC: Armed Forces Institute of Pathology; 1996.

5. Salcedo EE, Cohen GI, White RD, Davison MB. Cardiac tumors: diagnosis and management. Curr Probl Cardiol. 1992;17:73-137. 